solved by the scientists themselves. They must agree to resist the blandishments of the less scrupulous publishers, who cannot be controlled in any other way. It is natural that publishers should be keen to build up scientific lists, and they may not really be capable of judging quality. The other part of the problem is that even if the scientists agreed to exercise due restraint, there would still be, and increasingly so, more material than can be digested in its present form by those for whom it is written. A revolution in the means of communicating scientific knowledge therefore seems inevitable. This may take many different forms : microfilming to save library space, abstracting, and the compilation of bibliographies to guide the reader to the essential reading. It would be helpful if scientists and publishers could get together to consider the directions in which these developments could most usefully be trained. D. Richten

\title{
HUMAN GROWTH
}

$\mathrm{T}$ HE recently formed Society for the Study of Human Biology holds each year a symposium on some topic bearing on the evolution, ecology or genetics of man, and these annual events bid fair to become of very wide interest. This year the subject was "Human Growth," and seven papers were given, under the chairmanship of the Society's president, Dr. A. C. Stevenson, and its vice-president, Prof. J. Z. Young. The Society's programme secretary, Dr. G. Ainsworth Harrison, who planned the programme, deserves much praise for his skill in so successfully composing the various views of human growth into a synoptic whole. Some points that the speakers made are given below: the full account of the proceedings is to be published this summer (Pergamon Press).

Prof. Adolph Schultz (Zurich) opened the proceedings with a paper on the comparison of changes during growth in man, apes and monkeys. He emphasized the great importance of such comparative growth studies, pointing out that phylogenetic change results primarily from a modification in the inherited plan of growth or development. Thus an understanding of the evolution of the specific characters of man was largely dependent upon knowledge of the ontogeny of these characters among primates. For example, the cranio-vertebral joint was situated farther forward in man than in any other primate or even any other mammal. But this became an exclusively human attribute only during postnatal life, for the foetuses of all simian primates, in contrast to prosimians and other mammals, were characterized by occipital joints situated far towards the mouth. Post-natally in apes and monkeys the joints were moved backward in position by differential skull growth; but in man this happened to a lesser degree.

In discussing prenatal growth Prof. Schultz showed how in monkeys and man the full-term foetal head fitted the birth canal precisely, whereas in apes the head was considerably smaller than the pelvic ring. Thus in contrast to the apes, neither monkey nor man could afford to go on growing longer in utero. The reasons were probably different, however, for monkeys reached a higher degree of skeletal maturity at birth than apes, and presumably birth waited on this. Man, however, was even less skeletally mature at birth than apes, and in this case it was the great growth of the fotal head that was the limiting factor.

These skeletal ossification data served well to show how evolution worked through alteration in the relative timing of patterns of growth, for the general sequence of appearance and fusion of ossification centres was similar in all primates; it was the timing in relation to other events of growth that differed. Prof. Schultz left no doubt in the minds of his hearers that longitudinal growth-studies of subhuman primates were a high priority in the investigation of human evolutionary change.

Dr. Wilma Israelsohn (Institute of Child Health, University of London) described some of the modes of analysis of human growth data, taking many of her illustrations from the data of the Harpenden Growth Study, which included a number of children measured by the same anthropometrist every six months over a period of eleven years. Dr. Israelsohn stressed the difference between such longitudinal studies and cross-sectional surveys, and emphasized how statistical methods appropriate to the survey type of data became hopelessly inefficient if applied unaltered to longitudinal records. She described some of the recent attempts to fit useful curves to longitudinal growth data, and said that at least two curves were needed to cover the period from birth to maturity. Up to adolescence the simple formulation, stature (for example) $=a+b t+c \log t$ where $t$ was age, gave surprisingly close fits to the data, and after the adolescent spurt of growth had begun the Gompertz curve, also with three parameters, fitted excellently. More complicated form changes involving not one but several measurements could be followed by the method of transformed co-ordinate grids.

Dr. J. M. Tanner (Institute of Child Health, University of London) discussed the genetics of human growth. Like Prof. Schultz, he stressed how species, and also individual differences in adult morphology, depended on genetically determined differential growth gradients during foetal and post-natal growth. He quoted data showing that the fundamental control of the rate of development in man was genetical ; thus the age of menarche, the first menstrual period, was probably determined in optimal environmental circumstances by many genes of small effect, like stature. Mother-daughter and sister-sister correlations were about $0 \cdot 4$, and the average difference between identical twins in reaching menarche was about 2 months, compared to about a year in sisters. Skeletal maturity appeared to be similarly inherited, as did many of the more intricate details of the growth curves of body measurements. Dr. Tanner described three regional growth gradients as occurring in man, the well-known cephalocaudad one, a distal-proximal one in the limbs, and a second-to-fifth phalanx one in hand and foot. He ended with a brief account of his own and his colleagues' recent work on the skeletal maturity of $X X Y$ and $X O$ individuals which, he thought, showed that the retardation of development in the male as compared to the female, seen in all primates and perhaps all mammals, was due to genes on the $Y$ chromosome, possibly closely related to those causing differentiation of the male gonad. 
Dr. D. F. Roberts (Department of Human Anatomy, University of Oxford), discussed the effects of race and elimate on growth, as exemplified in his studies of tribal African children. At all ages the African children had a lower weight for height than Europeans, and this, Dr. Roberts thought, could not by any means be ascribed simply to lack of nutrition. The degree of weight reduction and linearity of body build was closely associated with the mean annual temperature of the region studied and reached its maximum in the Nilotics. Whether climate exerted a direct effect upon growth, or whether the results came about through racial adaptation to habitat through selection, Dr. Roberts could not say. $\mathrm{He}$ stressed the need for more detailed investigations of the growth of children in tropical countries, and for the investigation of children exposed to varying climatic conditions during their growth period.

Dr. Roy Acheson (Guy's Hospital) described the effects of malnutrition and illness on growth. Though some of the social class differences in the height and weight of children and adults might be genetical in origin and due to social stratification and selective social migration, most were due to environmental causes. Studies in the Oxford Child Health Survey of the effect of adverse environment on height and skeletal maturity had convinced him that the former was more affected by illness than the latter, with the probable consequence that some degree of stunting of the adult would occur. The hormonal mechanisms by which this came about were obscure, and invited increased attention; they evidently involved the balance of secretions of growth hormone, adrenal hormones, insulin and thyroid.

Prof. T. McKeown (Department of Social Medicine, University of Birmingham) discussed influences affecting human prenatal growth. It seemed that up to 27 weeks foetal weight was independent of the number of fotuses in the uterus, but after that the growth-rate of twins fell below that of singletons. Growth began to be retarded when the weight of the foetus or fœetuses was about $7 \mathrm{lb}$., and in singletons from the thirty-sixth week to birth retardation clearly occurred. Whether this maternal effect was due to local uterine factors or to systemic ones was not surely known, nor whether the degree of retardation suffered by the foetus had any effect in later life. Prof. Mckeown thought that the retarda. tion period, that is the last four weeks before birth, was a period of considerable growth difficulty in man, and felt that increased attention should be paid to it, both prophylactically and therapeutically.

Dr. A. W. Boyne (Rowett Research Institute, Aberdeen) discussed some aspects of the well-known secular trend to higher weight and height of children at all ages. He quoted French and Scandanavian data, as well as British, which left no doubt that an increase in final adult height had been occurring as well as an earlier achievement of adolescence and full stature. Some evidence pointed to this increase in adult stature having been greater in the lower socio-economic groups than in those who had always been well fed and well housed. Dr. Boyne discussed the changes in 11-year-old intelligence quotient in some Scottish data, and in particular the increase of girls' intelligence quotient relative to boys' at this age. He suggested this might have the same explanation as a similar increase in sex difference in weight, which was certainly due to the earlier occurrence of the adolescent growth spurt. Though his premise demanded the existence of a growth spurt in intelligence quotient at adolescence, the consensus of opinion was against any such view.

Each of the papers was followed by a lively discussion. These discussions ranged over the manner of man's evolution by differential growth-rates of brain and other parts, the adaptation of different races to different habitats by differential patterns of growth, the occurrence of homeorrhesis in man and the greater stability of growth of the female under stress than that of the hemizygous male, and the relation of growth of the body to the development of mental skills.

A whole day's meeting to discuss human growth would have been unthinkable in Britain even ten years ago, and the Society for the Study of Human Biology is much to be congratulated for furthering the development of this important subject.

J. M. TANNER

\section{THE ROCKEFELLER FOUNDATION}

$\mathrm{T}$ HE President's review, reprinted from the Annual Report, 1958, of the Rockefellex Foundation together with Dr. Warren Weaver's report, "A Quarter Century in the Natural Sciences", records appropriations by the Foundation during the year totalling $31,592,157$ dollars, of which $6,274,205$ dollars were for agriculture, 6,201,225 dollars for biological and medical research, 4,239,160 dollars for medical education and public health, 4,300,160 dollars for the social sciences, $3,620,582$ dollars for the humanities, and $3,266,575$ dollars for supporting services. The total included funds for 279 Rockefeller Foundation Fellowships in fifty-one countries for advanced study outside the recipient's own country, and 301 other Fellows continued their work in 1958 through earlier awards. Dean Rusk's general comments are appropriate to the increasing interest in economic and technical assistance to the underdeveloped countries. The expansion of such development programmes has compelled the Rockefeller Foundation to consider carefully where it can make its best contribution, and Dean Rusk maintains that the Foundation's own experience emphasizes the dependance of significant social and economic advance upon trained leadership and the severe limitation of large development programmes by the lack of quali. fied people. The need for professional competence is likely to be far greater than official development plans usually contemplated, and accordingly the Foundation's most significant contribution is likely to be in the preparation of competent men and women for roles of leadership and, so far as the underdeveloped countries are concerned, in the effective application of existing knowledge to their practical needs, with an emphasis upon fundamental research.

Dean Rusk points out that the 1958 awards bring the total of Foundation fellowships to 8,117 , and that scholarships, training grants and other more directly administered training aids may be used where the more formal fellowships would not be appropriate. Grants are also made to permit other 